\title{
Effect of Oral carnosine supplementation on urinary TGF- $\beta$ in diabetic nephropathy: a randomized controlled trial
}

\author{
Narongrit Siriwattanasit, Bancha Satirapoj (i] and Ouppatham Supasyndh
}

\begin{abstract}
Background: Activation of the transforming growth factor beta (TGF- $\beta$ ) pathway is a significant contributor to the pathogenesis of diabetic nephropathy. Carnosine is a dipeptide that can inhibit TGF- $\beta$ synthesis. We tested the hypothesis that carnosine supplement added to standard therapy will result in reduced urinary TGF- $\beta$ levels among patients with diabetic nephropathy.
\end{abstract}

Methods: We randomly assigned 40 patients with diabetic nephropathy and albuminuria 30-299 mg/day to treatment with carnosine ( $2 \mathrm{~g} /$ day) or placebo for 12 weeks. Urinary TGF- $\beta$ level was determined using ELISA, urine albumin was ascertained by immunonephelometric assay, and renal function and metabolic profiles were determined at baseline and during 12 weeks of active treatment. Primary outcome was decrease in urinary levels of TGF- $\beta$.

Results: The 2 groups were comparable for baseline characteristics, blood pressure, urine albumin, urine TGF- $\beta$ and renal function measurements. Urinary TGF- $\beta$ significantly decreased with carnosine supplement $(-17.8 \%$ of the baseline values), whereas it tended to increase with placebo (+ $16.9 \%$ of the baseline values) (between-group difference $P$ <0.05). However, blood urea nitrogen, serum creatinine, glomerular filtration rate and other biochemical parameters remained unchanged during the study period including urinary albuminuria. Both groups were well tolerated with no serious side-effects.

Conclusions: These data indicated an additional renoprotective effect of oral supplementation with carnosine to decrease urinary TGF- $\beta$ level that serves as a marker of renal injury in diabetic nephropathy.

Trial registration: Thai Clinical Trials, TCTR20200724002. Retrospectively Registered 24 July 2020.

Keywords: Carnosine, Diabetic nephropathy, Urinary TGF- $\beta$

\section{Background}

Diabetic nephropathy is the leading cause of chronic kidney disease (CKD), and the foremost cause of end stage renal disease (ESRD) [1]. The standard treatment for diabetic nephropathy includes controlling glycemia and blood pressure and reducing albumin leakage in urine using angiotensin converting enzyme inhibitors

\footnotetext{
* Correspondence: satirapoj@yahoo.com

Department of Medicine, Division of Nephrology, Phramongkutklao Hospital and College of Medicine, Bangkok 10400, Thailand
}

(ACEIs) or angiotensin receptor blockers (ARBs) [2]. These can reduce the number of patients receiving renal replacement therapy which eventually reduces cost of treatment for patients with diabetic nephropathy.

Hyperglycemia induces an abnormal activation of glucose-dependent pathways. i.e., the polyol pathway, hexosamine pathway and protein kinase $\mathrm{C}$ pathway in producing multiple substances, including transforming growth factor beta (TGF- $\beta$ ), vascular endothelial growth factor (VEGF), interleukine-1 (IL-1), interleukine-6 (IL- 
6) and tissue necrosis factor (TNF) [3, 4]. Increased urinary TGF- $\beta$ level among patients with diabetes stimulates the canonical pathway (ALK 5, Smad 2/3) and alternate pathway (ALK 1, Smad 1/5) [5]. The activation of the canonical pathway induces extracellular matrix accumulation at the glomerular basement membrane (GBM) and mesangium. In addition, the activation of the alternate pathway induces podocyte injury causing foot process effacement. Therefore, TGF- $\beta$ and activation of the metabolic pathway are important factors in developing diabetic nephropathy [6]. Treatment to reduce TGF- $\beta$ level in the urine may be able to slow the deterioration of diabetic nephropathy [7].

Carnosine is an amino acid found in nature, synthesized from L-histidine and beta-alanine (carnosine synthase) and degraded by the enzyme carnosinase [8]. Carnosine has many biological qualities that can slow CKD progression and prevent diabetic nephropathy from developing $[9,10]$. One of the proposed mechanisms is that it inhibits the synthesis of TGF- $\beta$ [11]. It has been hypothesized that individuals with two copies of the CNDP1 Mannheim have lower activity of plasma carnosinase, leading to higher plasma carnosine concentrations and a lower risk of diabetic nephropathy [11]. One study has shown that oral carnosine supplementation could reduce albuminuria and urinary alpha- $1 \mathrm{mi}-$ croglobulin level in type 1 diabetes [12]. Presently, no studies have yet been conducted among adult type 2 diabetes mellitus (T2DM) patients with diabetic nephropathy. The study aimed to assess the effect of oral carnosine supplementation on levels or urinary TGF- $\beta$ and albumin in patients with T2DM.

\section{Methods}

The study was a double-blind randomized controlled trial, comparing carnosine supplementation with placebo, alongside conventional treatment. The study was conducted among patients with T2DM treated at Phramongkutklao Hospital between 1 April 2018 and 31 March 2019, with all subjects selected by inclusion criteria. There was assistant researcher who recruited and enrolled participants in this study. Drug administration was according to a predetermined schedule generated from block of four random numbers in a 1:1 ratio based on a computer-generated randomization sequence maintained within the investigational drug pharmacy with allocation concealment by opaque sequentially numbered sealed envelope. As shown in Fig. 1. Group 1 supplemented $2 \mathrm{~g}$ /day oral carnosine (Tokai Bussan CO., LTD, Tokyo, Japan.) in gelatin capsules for 12 weeks. The dose was split into $2 \times 500 \mathrm{mg}$ taken after breakfast and dinner. Group 2 followed the same schedule but consumed a matched placebo containing starch. The participants had to take 2 capsules each time, after breakfast and dinner for 12 weeks, the same as group 1 . The study complies with the Declaration of Helsinki (1964). The study was registered at Thai Clinical Trials Registry (TCTR) (TCTR20200724002).

The inclusion criteria included T2DM with diabetic nephropathy according to KDOQI Guidelines and

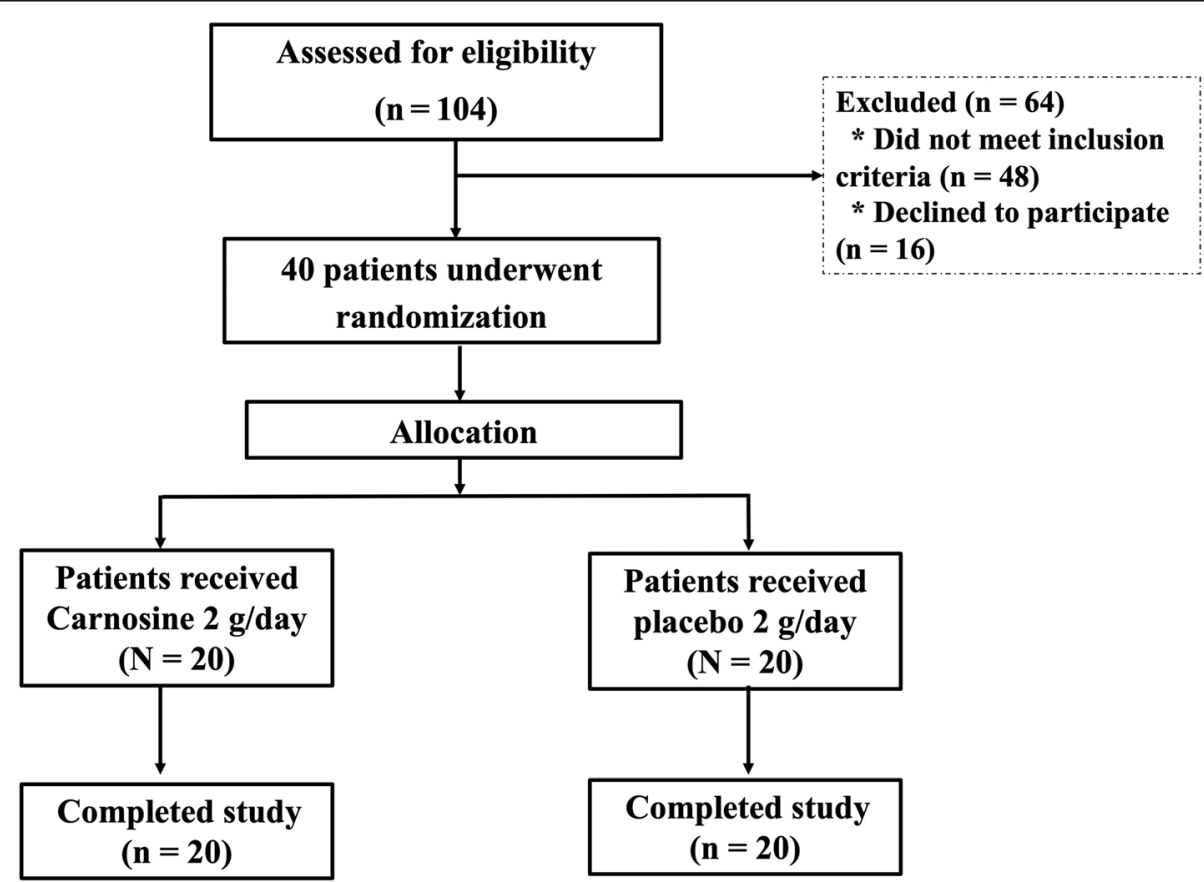

Fig. 1 Flow chart of study 
Chronic Kidney Disease 2007 criteria [13], age of 18 years old or older, urine albumin-creatinine ratio (UACR) of 30 to $299 \mathrm{mg} / \mathrm{g}$ creatinine (Cr) at least two in three within three to 6 months, stable dose of ACEIs or ARBs for blood pressure control at least 3 months before enrolling, and stable hemoglobinA1C (HbA1C) within 3 months before the study. The exclusion criteria comprised active infections, CKD from nondiabetic cause, advanced malignancy, history of hypersensitivity to protein nutrients, problems with nutrient absorption of the gastro-intestinal tract and liver disease.

The data we collected before and after in this study, were relevant information on diabetic nephropathy, including diagnostic criteria, duration of the disease and complications of diabetes mellitus such as diabetic retinopathy and diabetic neuropathy. Also, other underlying diseases, including hypertension, heart disease, liver disease, infectious diseases and malignancy were recorded. The history of medication including antihypertensive drugs and lipid lowering agents were recorded. Physical examination data including height, weight, blood pressure and body mass index (BMI) were collected. All subjects fasted for at least $12 \mathrm{~h}$ overnight before all blood drawing. The laboratory tests including fasting plasma glucose (FPG), HbA1C, blood urea nitrogen, Cr, calculation of estimated glomerular infiltration rate using the 2009 Chronic Kidney Disease Epidemiology Collaboration Equation, total cholesterol, triglyceride, low density lipoprotein and high-density lipoprotein were noted.

Thirty milliliters of fresh urine were centrifuged at $4000 \mathrm{rpm}$ for $10 \mathrm{~min}$, then stored at $-80^{\circ} \mathrm{C}$ until assayed. Urinary TGF- $\beta$ level were tested by enzymelinked immunosorbent assay (IBL-America, Inc. Minneapolis, MN). All specimens were diluted often to obtain concentration at the optimal density according to the ELISA kit instruction. Coefficients of variation for urine tubular biomarkers assays were $<10 \%$, for intra-assay and inter-assay variation. UACR by immunonephelometric assay method, before and after receiving carnosine or placebo for a period of 12 weeks is shown in Fig. 1.

\section{Follow-up study results}

The researcher verified consistent carnosine intake by asking for the remaining tablets and followed up the side effects of carnosine intake by using the adverse effects assessment form (Naranjo's algorithm) [14]. Data of adherence to oral carnosine intake was recorded. The primary outcome was the change of urinary TGF- $\beta$ level after 12 weeks in the oral carnosine supplementation group, compared with that of the placebo group. The secondary outcome was the improving level of UACR after 12 weeks in the oral carnosine supplementation group compared with that of the placebo group.
Table 1 Baseline characteristics of patients

\begin{tabular}{|c|c|c|c|}
\hline Variables & $\begin{array}{l}\text { Placebo } \\
(N=20)\end{array}$ & $\begin{array}{l}\text { Carnosine } \\
(N=20)\end{array}$ & $P$ value \\
\hline Male, n (\%) & $4(20.0)$ & $11(55.0)$ & 0.022 \\
\hline Age (years) & $57.0 \pm 6.9$ & $55.6 \pm 4.8$ & 0.463 \\
\hline Duration (years) & $13.0 \pm 8.8$ & $10.5 \pm 6.5$ & 0.323 \\
\hline Body weight (kg) & $73.2 \pm 15.3$ & $81.6 \pm 18.5$ & 0.127 \\
\hline Body mass index $\left(\mathrm{kg} / \mathrm{m}^{2}\right)$ & $28.4 \pm 5.2$ & $30.3 \pm 5.6$ & 0.284 \\
\hline Systolic blood pressure $(\mathrm{mmHg})$ & $134.2 \pm 16.4$ & $134.1 \pm 11.8$ & 0.965 \\
\hline Diastolic blood pressure $(\mathrm{mmHg})$ & $78.2 \pm 7.0$ & $78.6 \pm 11.5$ & 0.895 \\
\hline \multicolumn{4}{|l|}{ Comorbid diseases (N, \%) } \\
\hline Hypertension & $14(70.0)$ & $17(85.0)$ & 0.451 \\
\hline Dyslipidemia & $17(85.0)$ & $16(80.0)$ & 1.000 \\
\hline Coronary heart disease & $1(5.0)$ & - & 1.000 \\
\hline Chronic lung disease & - & $1(5.0)$ & 1.000 \\
\hline \multicolumn{4}{|l|}{ Anti-hypertensive drugs ( $\mathrm{N}, \%)$} \\
\hline ACEl & $1(5.0)$ & $3(15.0)$ & 0.605 \\
\hline ARB & $11(55.0)$ & $12(60.0)$ & 0.749 \\
\hline $\mathrm{CCB}$ & $9(45.0)$ & $13(65.0)$ & 0.204 \\
\hline Thiazide & $3(15.0)$ & $1(5.0)$ & 0.605 \\
\hline Hydralazine & $1(5.0)$ & - & 1.000 \\
\hline Doxazocin & $2(10.0)$ & $3(15.0)$ & 1.000 \\
\hline \multicolumn{4}{|l|}{ Anti-glycemic drugs (N, \%) } \\
\hline Metformin & $15(75.0)$ & $20(100.0)$ & 0.047 \\
\hline Sulfonylurea & $7(35.0)$ & $5(25.0)$ & 0.490 \\
\hline Thiazolidinedione & $5(25.0)$ & $9(45.0)$ & 0.185 \\
\hline DPP4-inhibitor & $7(35.0)$ & $5(25.0)$ & 0.490 \\
\hline SGLT-2 inhibitor & $7(35.0)$ & $2(10.0)$ & 0.127 \\
\hline GLP-1 agonist & $1(5.0)$ & $2(10.0)$ & 1.000 \\
\hline \multicolumn{4}{|l|}{ Laboratory parameters } \\
\hline $\mathrm{FPG}(\mathrm{mg} / \mathrm{dL})$ & $131.0 \pm 30.3$ & $168.6 \pm 52.7$ & 0.009 \\
\hline HemoglobinA1C (\%) & $7.8 \pm 1.8$ & $7.8 \pm 1.5$ & 0.971 \\
\hline Triglycerides (mg/dL) & $159.4 \pm 88.8$ & $157.5 \pm 112.9$ & 0.953 \\
\hline Cholesterol (mg/dL) & $156.6 \pm 37.6$ & $157.8 \pm 29.9$ & 0.913 \\
\hline LDL-cholesterol (mg/dL) & $92.3 \pm 35.8$ & $114.9 \pm 81.1$ & 0.080 \\
\hline HDL-cholesterol (mg/dL) & $50.9 \pm 2.6$ & $49.4 \pm 2.3$ & 0.262 \\
\hline BUN (mg/dL) & $17.1 \pm 7.2$ & $15.6 \pm 5.7$ & 0.456 \\
\hline Creatinine (mg/dL) & $0.9 \pm 0.3$ & $0.9 \pm 0.2$ & 0.677 \\
\hline GFR (mL/min/1.73 $\left.\mathrm{m}^{2}\right)$ & $78.6 \pm 22.1$ & $81.6 \pm 19.7$ & 0.655 \\
\hline Urine TGF- $\beta$ (pg/mgCr) & $82.9 \pm 57.1$ & $89.1 \pm 75.9$ & 0.775 \\
\hline UACR (mg/gCr) & $114.7 \pm 64.8$ & $114.8 \pm 56.4$ & 0.997 \\
\hline
\end{tabular}

Data in the table are shown with average \pm standard deviation and percentages.

$A C E I$ angiotensin converting enzyme inhibitor, $A R B$ angiotensin receptor blockade, BUN blood urea nitrogen, CCB Calcium channel blocker, DPP4inhibitor dipeptidyl peptidase-4 inhibitor, SGLT-2 inhibitor sodium glucose cotransporter inhibitor, GLP-1 agonist glucagon-like peptide-1 receptor agonist, GFR estimated glomerular filtration rate, $L D L$ low density lipoprotein cholesterol, HDL high density lipoprotein cholesterol 
A. Mean change of UTGF- $\beta / \mathrm{cr}(\mathrm{pg} / \mathrm{mg})$

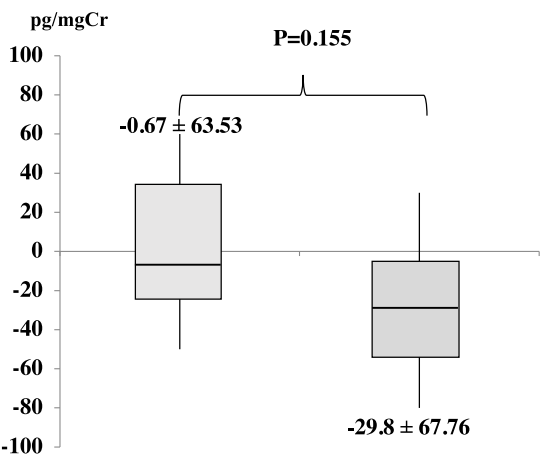

Placebo

Carnosine
B. Percentage of mean change of UTGF- $\beta / \mathrm{cr}(\mathrm{pg} / \mathrm{mg})$

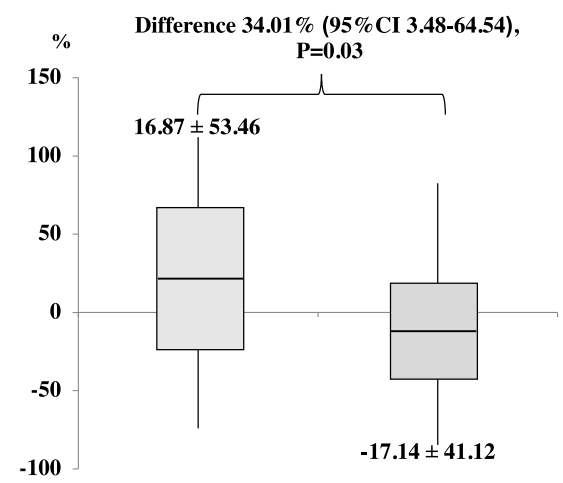

Placebo

Carnosine

Fig. 2 Change of urine TGF- $\beta$ after treatment. Box-and-whisker-plot diagrams show the (A) mean change of urine TGF- $\beta$ (pg/mgCr) and (B) percentage of mean change of urine TGF- $\beta$ ( $\mathrm{pg} / \mathrm{mgCr}$ ) after 12 weeks of taking carnosine

\section{Statistical analysis}

Data were analyzed using the commercially available SPSS 22.0 statistical software program (SPSS, Chicago, IL, US). Descriptive statistics were used to present general information, laboratory results and urinary substances measurement level, including percentages, averages, and standard deviations in the case of normal distributed continuous data. Inferential statistics was used to compare between general information, laboratory results and the percentage changes of variables in the oral carnosine supplementation and placebo groups, based on Student's test statistics. Pearson chi-square test or Fisher's exact test was used for discrete or categorical variables. Two-way analysis of variance (ANOVA) with repeated measures and paired-sample $t$ tests was used for the continuous variables and presented by the relative risk of $95 \%$ confidence intervals with $p$-value less than 0.05 , regarded as statistically significant.

\section{Results}

From the screening, of a total of 104 patients with T2DM and nephropathy, 64 were excluded. The included 40 patients were randomly divided in two groups and all of them were $100 \%$ adherent to the carnosine or placebo prescription based on pill counts. Baseline laboratory tests and metabolic profiles were found between the two groups as shown in Table 1.

\section{Change of urine TGF- $\beta$ after treatment}

After 12 weeks, no significant differences were found on mean change of urine TGF- $\beta$ between the two groups as shown in Fig. 2A. After additional analysis, the oral
A. Mean change of $\mathrm{UACR}(\mathrm{mg} / \mathrm{gCr})$

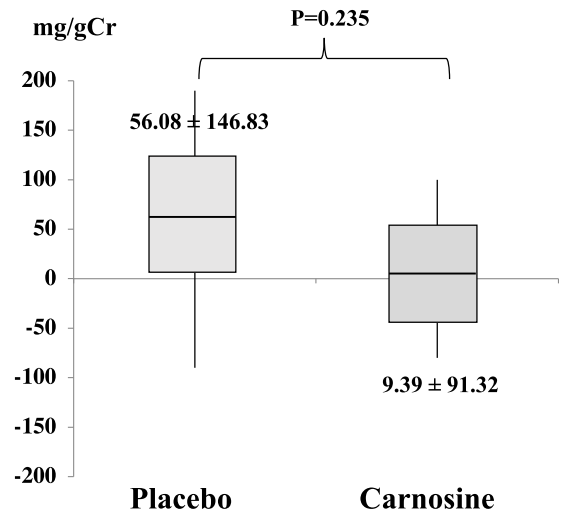

B. Percentage of mean change of UACR $(\mathrm{mg} / \mathrm{gCr})$

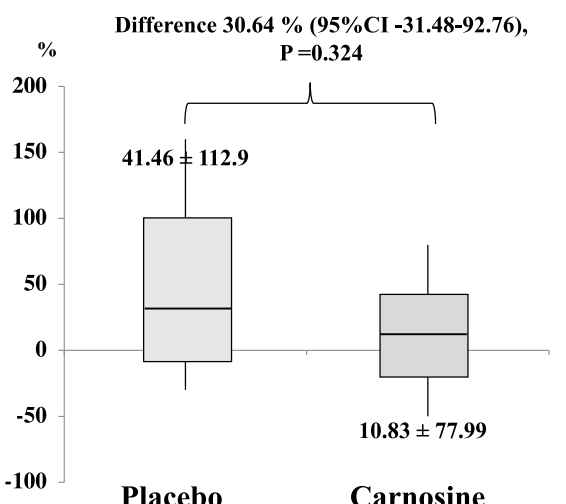

Fig. 3 Change of urine albumin after treatment. Box-and-whisker-plot diagram shows the (A) mean change of UACR and (B) percentage of mean change of UACR (mg/gCr) after 12 weeks of taking carnosine 
Table 2 Change of variables after 12 weeks of treatment

\begin{tabular}{llll}
\hline Variables & $\begin{array}{l}\text { Placebo } \\
(\mathbf{N = 2 0})\end{array}$ & $\begin{array}{l}\text { Carnosine } \\
(\mathbf{N = 2 0 )}\end{array}$ & $\boldsymbol{P}$ value \\
\hline Body weight $(\mathrm{kg})$ & $-0.65 \pm 1.64$ & $-0.22 \pm 2.23$ & 0.167 \\
Body mass index $\left(\mathrm{kg} / \mathrm{m}^{2}\right)$ & $-0.25 \pm 0.65$ & $-0.18 \pm 0.97$ & 0.101 \\
Systolic blood pressure $(\mathrm{mmHg})$ & $-0.90 \pm 7.38$ & $-3.15 \pm 12.40$ & 0.217 \\
Diastolic blood pressure (mmHg) & $-1.95 \pm 6.20$ & $0.35 \pm 6.32$ & 0.424 \\
BUN (mg/dL) & $1.76 \pm 5.23$ & $0.48 \pm 5.59$ & 0.199 \\
Creatinine (mg/dL) & $0.01 \pm 0.11$ & $-0.03 \pm 0.13$ & 0.523 \\
GFR (mL/min/1.73m $)$ & $-0.29 \pm 8.04$ & $4.18 \pm 11.82$ & 0.232 \\
Fasting plasma glucose (mg/dL) & $-25.9 \pm 73.6$ & $-16.7 \pm 73.59$ & 0.696 \\
HemoglobinA1C (\%) & $-0.07 \pm 1.46$ & $-0.33 \pm 0.78$ & 0.486 \\
LDL (mg/dL) & $10.30 \pm 47.40$ & $-23.40 \pm 86.60$ & 0.556 \\
HDL (mg/dL) & $1.60 \pm 12.10$ & $-1.90 \pm 11.0$ & 0.929 \\
Cholesterol (mg/dL) & $9.84 \pm 51.90$ & $-10.10 \pm 41.60$ & 0.984 \\
Triglyceride (mg/dL) & $-9.20 \pm 70.70$ & $-0.50 \pm 63.70$ & 0.653 \\
\hline
\end{tabular}

Data in the table are shown with average + standard deviation. BUN blood urea nitrogen, GF glomerular filtration rate, $L D L$ low density lipoprotein cholesterol, $H D L$ high density lipoprotein cholesterol

carnosine supplement group had a decreased percentage of mean change of urine TGF- $\beta$ Cr ratio from baseline by $17.14 \%$. Whereas the percentage of placebo increased by $16.87 \%$. Both groups had a percent mean difference of 34.01 and differed significantly $(P=0.03$, 95\% CI 3.48 to 64.54 ), as shown in Fig. $2 \mathrm{~B}$.

\section{Change of urine albumin after treatment}

The percentage of mean change of UACR increased from baseline by $10.83 \%$ (mean $\pm \mathrm{SD}=10.83 \pm 77.99 \mathrm{mg}$ /

Table 3 Mean variables at 12 weeks of treatment

\begin{tabular}{llll}
\hline Variables & $\begin{array}{l}\text { Placebo } \\
(\mathbf{N = 2 0})\end{array}$ & $\begin{array}{l}\text { Carnosine } \\
(\mathbf{N = 2 0})\end{array}$ & $\boldsymbol{P}$ value \\
\hline Body weight $(\mathrm{kg})$ & $72.54 \pm 14.7$ & $81.34 \pm 18.9$ & 0.117 \\
Body mass index $\left(\mathrm{kg} / \mathrm{m}^{2}\right)$ & $28.18 \pm 5.0$ & $30.12 \pm 5.6$ & 0.268 \\
Systolic blood pressure $(\mathrm{mmHg})$ & $133.35 \pm 16.5$ & $130.9 \pm 13.6$ & 0.611 \\
Diastolic blood pressure $(\mathrm{mmHg})$ & $76.2 \pm 7.9$ & $78.9 \pm 11.7$ & 0.763 \\
BUN (mg/dL) & $18.89 \pm 5.6$ & $16.06 \pm 5.9$ & 0.217 \\
Creatinine (mg/dL) & $0.895 \pm 0.03$ & $0.896 \pm 0.3$ & 0.832 \\
GFR (mL/min/1.73m $)$ & $78.34 \pm 23.6$ & $85.78 \pm 20.2$ & 0.434 \\
Fasting plasma glucose (mg/dL) & $156.85 \pm 70.2$ & $151.9 \pm 47.5$ & 0.171 \\
HemoglobinA1C (\%) & $7.86 \pm 1.8$ & $7.48 \pm 1.3$ & 0.716 \\
LDL (mg/dL) & $102.59 \pm 48.1$ & $91.5 \pm 35.2$ & 0.656 \\
HDL (mg/dL) & $51.17 \pm 13.2$ & $46.89 \pm 9.2$ & 0.404 \\
Cholesterol (mg/dL) & $166.43 \pm 51.6$ & $147.6 \pm 35.1$ & 0.383 \\
Triglyceride (mg/dL) & $150.22 \pm 77.1$ & $157.02 \pm 71.7$ & 0.926 \\
\hline
\end{tabular}

Data in the table are shown with average + standard deviation. $B U N$ blood urea nitrogen, GF glomerular filtration rate, $L D L$ low density lipoprotein cholesterol, HDL high density lipoprotein cholesterol
$\mathrm{gCr}$ ) in the carnosine group. However, in the placebo group, the percentage of mean change of UACR increased by $41.46 \%$ (mean $\pm \mathrm{SD}=41.46 \pm 112.9 \mathrm{mg} / \mathrm{gCr}$ ). Both groups exhibited a percent mean difference of $30.64 \%$, without significance $(P=0.324,95 \%$ CI -31.48 to 92.76) and did not differ significantly concerning mean change of urine albuminuria as shown in Fig. $3 \mathrm{~A}$ and $\mathrm{B}$.

Metabolic profiles and adverse events after treatment After 12 weeks, BMI, blood pressure, renal function, $\mathrm{HbA} 1 \mathrm{C}$ and lipid profiles of all patients remained unchanged from baseline, as shown in Table 2 and Table 3. Our participants did not experience any side effects of carnosine during the study.

\section{Discussion}

This study was the first randomized controlled trial showing the statistically significant differences in the data regarding oral carnosine supplementation among patients with T2DM and nephropathy, to reduced urinary TGF- $\beta$ compared with placebo. This was consistent with related research investigating patients with type 1 diabetes and nephropathy. Elbarbary et al. reported that carnosine could reduce urine alpha-1 microglobulin, which is a urine biomarker of glomerular and tubular injury among diabetic patients, as well as urinary TGF- $\beta$ [12]. Several studies in vitro studies and animal models also demonstrated anti-apoptosis, anti-inflammatory, anti-oxidant, antiglycation, antiproteinuric and vasculoprotective effects of carnosine [15-18].

Reduced urinary TGF- $\beta$ is a biomarker for CKD progression [7]. It has been shown that carnosine may have a reno-protective effect on ischemia/reperfusion-induced acute kidney injury in animal models [19] and attenuates the development of patients with T2DM and nephropathy [20]. Whereas we found that oral carnosine supplementation did not reduce urine albumin, which differed from the study of Elbarbary et al. [12]. The finding might be explained in that baseline patients' conditions in this study were more severe regarding the degree of diabetic nephropathy. Higher age, urine albumin and comorbid illness including hypertension, dyslipidemia, and obesity were observed in our study. On the contrary, the subjects in related studies had shorter duration of diabetes without history of underlying diseases reported. Our study found that early biomarkers of kidney injury including urine TGF- $\beta$ level was lower in the carnosine group. Thus, a follow-up of longer duration might show significantly decreased levels of urine albumin.

Additional renal benefits of carnosine treatment were improved glycemic and metabolic control [21, 22]. An in vivo study in diabetes-induced mice receiving carnosine supplements showed reduced FPG levels, decreased 
insulin resistance and increased $\beta$-cell mass [23-25]. In addition, a study of Elbarbary et al., investigated among children with type 1 diabetes mellitus found that oral carnosine supplementation for 12 weeks could significantly reduce HbA1C compared with placebo [12], which differed from our study. This was due to the difference in baseline $\mathrm{HbA1C}$ where average baseline HbA1C levels were $7.8 \%$ in our study and $8.2 \%$ in previous study [12]. Patients with T2DM in our study were already able to effectively control their HbA1C levels at $7.8 \%$, as we could not see any additional benefit of carnosine on reducing HbA1C level. Another in vitro study of Lee YT, et al. showed that carnosine could improve lipid metabolism [26]. Moreover, carnosine could reduce lipid peroxidation, atherogenic ApoB lipoproteins and triglycerides in plaques of mice [27]. The study among children with type 1 diabetes found that receiving carnosine for 12 weeks could improve cholesterol level [12]. The lipid outcome was undetected in our study, because approximately $80 \%$ of our adult subjects received strong lipid lowering agents.

The limitation of our study was that we did not evaluate major renal outcomes including ESRD, double serum $\mathrm{Cr}$ and dialysis. The main outcome was only biomarkers of kidney progression including urine TGF- $\beta$ and albumin. Due to the short duration, our study could not conclude any long-term effects of carnosine on urine TGF- $\beta$ reduction and renal outcomes. Therefore, the long-term side effects of carnosine are needed to be further investigated.

\section{Conclusion}

In summary, the study showed that oral carnosine supplementation could reduce urinary TGF- $\beta$ level in T2DM with diabetic nephropathy, but without significant effects on urine albumin, indicating an additional renoprotective effect from conventional therapy. Further study is needed to determine the long-term effects of oral carnosine supplementation on delayed renal progression in T2DM as a result of the decreased level of urinary TGF- $\beta$.

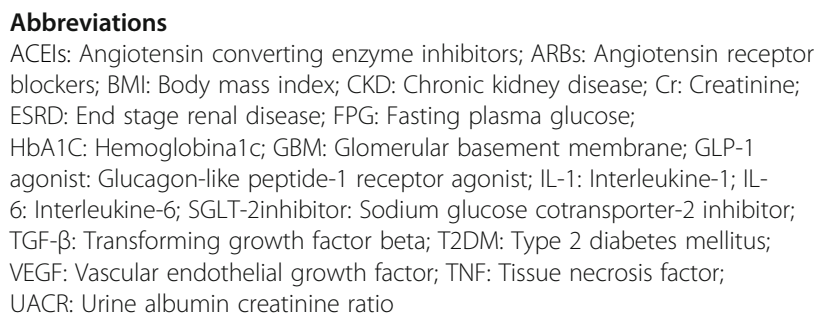

Abbreviations

ACEls: Angiotensin converting enzyme inhibitors; ARBs: Angiotensin receptor blockers; BMI: Body mass index; CKD: Chronic kidney disease; $\mathrm{Cr}$ : Creatinine; ESRD: End stage renal disease; FPG: Fasting plasma glucose; HbA1C: Hemoglobina1c; GBM: Glomerular basement membrane; GLP-1 agonist: Glucagon-like peptide-1 receptor agonist; IL-1: Interleukine-1; IL6: Interleukine-6; SGLT-2inhibitor: Sodium glucose cotransporter-2 inhibitor; TGF- $\beta$ : Transforming growth factor beta; T2DM: Type 2 diabetes mellitus; VEGF: Vascular endothelial growth factor; TNF: Tissue necrosis factor; UACR: Urine albumin creatinine ratio

\section{Acknowledgments}

I would like to express my deepest gratitude to all of my lecturers for their professional guidance, active motivation and valuable support. Moreover, I would like to thank to the Nephrology Department, Internal Medicine
Division, the Center for Biological Sciences and Development and Phramongkutklao Hospital for all their support.

\section{Authors' contributions}

NS, BS, and OS collected the data, drafted the article, reviewed the literature and revised it critically. NS provided valuable inputs in study design, data collection and literature review. BS provided revision of the draft. All authors read and approved the manuscript and met the criteria for authorship.

\section{Funding}

This study was supported by a grant from Department of Medicine, Phramongkutkloa Hospital, Bangkok, Thailand.

\section{Availability of data and materials}

The excel of individual clinical data used to support the findings of this study are available from the corresponding author upon request.

\section{Declarations}

Ethics approval and consent to participate

The study was approved by the Ethics Committee of Institutional Review Board. Royal Thai Army Medical Department (IRB Number S004h/57), Bangkok, Thailand. All patients gave written informed consent.

\section{Consent for publication}

Not applicable.

\section{Competing interests}

The authors declare that they have no competing interests.

Received: 25 July 2020 Accepted: 9 June 2021

Published online: 26 June 2021

\section{References}

1. Kim KS, Park SW, Cho YW, Kim SK. Higher prevalence and progression rate of chronic kidney disease in elderly patients with type 2 diabetes mellitus. Diabetes Metab J. 2018:42(3):224-32. https://doi.org/10.4093/dmj.2017.0065.

2. Satirapoj B, Adler SG. Prevalence and Management of Diabetic Nephropathy in Western countries. Kidney Dis (Basel). 2015;1(1):61-70. https://doi.org/1 $0.1159 / 000382028$

3. Schena FP, Gesualdo L. Pathogenetic mechanisms of diabetic nephropathy. J Am Soc Nephrol. 2005;16(Suppl 1):S30-3. https://doi.org/10.1681/ASN.2 004110970.

4. Satirapoj B, Adler SG. Comprehensive approach to diabetic nephropathy. Kidney Res Clin Pract. 2014;33(3):121-31. https://doi.org/10.1016/j.krcp.2014. 08.001 .

5. Zheng $X$, Bhalla $V$. The missing link: studying the alternative TGF-beta pathway provides a unifying theory for different components of diabetic nephropathy. Diabetes. 2015;64(6):1898-900. https://doi.org/10.2337/db150184.

6. Chang AS, Hathaway CK, Smithies O, Kakoki M. Transforming growth factorbeta1 and diabetic nephropathy. Am J Physiol Renal Physiol. 2016;310(8): F689-96. https://doi.org/10.1152/ajprenal.00502.2015.

7. Qiao YC, Chen YL, Pan YH, Ling W, Tian F, Zhang XX, et al. Changes of transforming growth factor beta 1 in patients with type 2 diabetes and diabetic nephropathy: a PRISMA-compliant systematic review and metaanalysis. Medicine (Baltimore). 2017;96(15):e6583. https://doi.org/10.1097/ MD.0000000000006583.

8. Hobart LJ, Seibel I, Yeargans GS, Seidler NW. Anti-crosslinking properties of carnosine: significance of histidine. Life Sci. 2004;75(11):1379-89. https://doi. org/10.1016/j.lfs.2004.05.002.

9. Reddy VP, Garrett MR, Perry G, Smith MA. Carnosine: a versatile antioxidant and antiglycating agent. Sci Aging Knowl Environ. 2005;2005(18):pe12. https://doi.org/10.1126/sageke.2005.18.pe12

10. Boldyrev AA, Aldini G, Derave W. Physiology and pathophysiology of carnosine. Physiol Rev. 2013;93(4):1803-45. https://doi.org/10.1152/physrev. 00039.2012

11. Janssen B, Hohenadel D, Brinkkoetter P, Peters V, Rind N, Fischer C, et al. Carnosine as a protective factor in diabetic nephropathy: association with a leucine repeat of the carnosinase gene CNDP1. Diabetes. 2005;54(8):2320-7. https://doi.org/10.2337/diabetes.54.8.2320. 
12. Elbarbary NS, Ismail EAR, El-Naggar AR, Hamouda MH, El-Hamamsy M. The effect of 12 weeks carnosine supplementation on renal functional integrity and oxidative stress in pediatric patients with diabetic nephropathy: a randomized placebo-controlled trial. Pediatr Diabetes. 2018:19(3):470-7. https://doi.org/10.1111/pedi.12564.

13. Saunders W: KDOQI clinical practice guidelines and clinical practice recommendations for diabetes and chronic kidney disease. 2007.

14. Naranjo CA, Busto U, Sellers EM, Sandor P, Ruiz I, Roberts E, et al. A method for estimating the probability of adverse drug reactions. Clin Pharm Ther. 1981;30(2):239-45. https://doi.org/10.1038/clpt.1981.154.

15. Peters V, Zschocke J, Schmitt CP. Carnosinase, diabetes mellitus and the potential relevance of carnosinase deficiency. J Inherit Metab Dis. 2018;41(1): 39-47. https://doi.org/10.1007/s10545-017-0099-2.

16. Peters V, Yard B, Schmitt CP. Carnosine and diabetic nephropathy. Curr Med Chem. 2020;27(11):1801-12. https://doi.org/10.2174/092986732666619032 6111851.

17. Liu XQ, Jiang L, Lei L, Nie ZY, Zhu W, Wang S, et al. Carnosine alleviates diabetic nephropathy by targeting GNMT, a key enzyme mediating renal inflammation and fibrosis. Clin Sci (Lond). 2020;134(23):3175-93. https://doi. org/10.1042/CS20201207.

18. Zhao K, Li Y, Wang Z, Han N, Wang Y. Carnosine protects mouse podocytes from high glucose induced apoptosis through PI3K/AKT and Nrf2 pathways. Biomed Res Int. 2019;2019:4348973.

19. Kurata H, Fujii T, Tsutsui H, Katayama T, Ohkita M, Takaoka M, et al. Renoprotective effects of $\mathrm{I}$-carnosine on ischemia/reperfusion-induced renal injury in rats. J Pharmacol Exp Ther. 2006;319(2):640-7. https://doi.org/1 0.1124/jpet.106.110122

20. Albrecht T, Schilperoort M, Zhang S, Braun JD, Qiu J, Rodriguez A, et al. Carnosine attenuates the development of both type 2 diabetes and diabetic nephropathy in BTBR Ob/Ob mice. Sci Rep. 2017;7(1):44492. https:// doi.org/10.1038/srep44492.

21. Karkabounas S, Papadopoulos N, Anastasiadou C, Gubili C, Peschos D, Daskalou T, et al. Effects of alpha-lipoic acid, carnosine, and thiamine supplementation in obese patients with type 2 diabetes mellitus: a randomized, double blind study. J Med Food. 2018;21(12):1197-203. https:// doi.org/10.1089/jmf.2018.0007.

22. Kilis-Pstrusinska K. Carnosine and kidney diseases: what we currently know? Curr Med Chem. 2020;27(11):1764-81. https://doi.org/10.2174/092986732 6666190730130024.

23. Sauerhofer S, Yuan G, Braun GS, Deinzer M, Neumaier M, Gretz N, et al. Lcarnosine, a substrate of carnosinase-1, influences glucose metabolism. Diabetes. 2007;56(10):2425-32. https://doi.org/10.2337/db07-0177.

24. Aldini G, Orioli M, Rossoni G, Savi F, Braidotti P, Vistoli G, et al. The carbonyl scavenger carnosine ameliorates dyslipidaemia and renal function in Zucker obese rats. J Cell Mol Med. 2011;15(6):1339-54. https://doi.org/10.1111/j.1 582-4934.2010.01101.x

25. Soliman KM, Abdul-Hamid M, Othman Al. Effect of carnosine on gentamicin-induced nephrotoxicity. Med Sci Monit. 2007;13(3):BR73-83.

26. Lee YT, Hsu CC, Lin MH, Liu KS, Yin MC. Histidine and carnosine delay diabetic deterioration in mice and protect human low density lipoprotein against oxidation and glycation. Eur J Pharmacol. 2005;513(1-2):145-50. https://doi.org/10.1016/j.ejphar.2005.02.010.

27. Yapislar H, Taskin E. L-carnosine alters some hemorheologic and lipid peroxidation parameters in nephrectomized rats. Med Sci Monit. 2014;20: 399-405. https://doi.org/10.12659/MSM.890528.

\section{Publisher's Note}

Springer Nature remains neutral with regard to jurisdictional claims in published maps and institutional affiliations.

Ready to submit your research? Choose BMC and benefit from:

- fast, convenient online submission

- thorough peer review by experienced researchers in your field

- rapid publication on acceptance

- support for research data, including large and complex data types

- gold Open Access which fosters wider collaboration and increased citations

- maximum visibility for your research: over $100 \mathrm{M}$ website views per year

At BMC, research is always in progress.

Learn more biomedcentral.com/submissions 